\title{
Influence of Carbon Content and Deformation Temperature on Ultra-Grain Refinement of Plain Carbon Steels by Means of Torsion Test
}

\author{
Welbert Ribeiro CALADO* and Ronaldo BARBOSA \\ Department of Metallurgical and Materials Engineering, Universidade Federal de Minas Gerais, Av. Antônio Carlos 6627, Grupo \\ 2, Sala 2230, Belo Horizonte, Minas Gerais, CEP 3409-1815 Brasil.
}

(Received on October 18, 2012; accepted on February 13, 2013)

\begin{abstract}
The effect of carbon content and deformation temperature on ultra-grain refinement of two plain carbon steels was studied. The steels samples were severely deformed by means of warm torsion tests. For both steels, the final microstructure consisted of ultrafine ferrite grains and small dispersed cementite particles depend on the test temperature. Increase in carbon content led to a decrease in the average ferrite grain size due to the presence of a higher volume fraction of cementite particles. Increasing in deformation temperature led to an increase in ferrite grain size. In addition, a critical strain for ultra grain refinement was reached for both steels. This critical deformation represents a minimum accumulated equivalent strain beyond which further significant grain size refinement is not more achievable. The higher the $\mathrm{C}$ content, the smaller this critical deformation was.
\end{abstract}

KEY WORDS: ultrafine grained steel; cementite particles; warm torsion test; grain boundaries; mechanical properties; microstructure; critical deformation.

\section{Introduction}

In recent years, ultrafine grained (UFG) steels have been studied with great interest by industries and universities in several countries, these great interest is due the unique and exclusive property of grain refinement of improve the strength without toughness degradation. Severe Plastic Deformation processes such as Accumulative Roll-Bonding (ARB), Equal Channel Angular Pressing (ECAP) and High Pressure Torsion (HPT) have been frequently used to obtain UFG microstructures. ${ }^{1-6)}$ However, alternatives techniques such as severe torsion test applying an ARB schedule ${ }^{7)}$ and warm caliber rolling ${ }^{8)}$ has been used with relatively successful for UFG production. The ARB and ECAP techniques introduce high heterogeneities concerning temperature, strain and strain rate distribution within the samples. ECAP introduces strain, strain rate and temperature heterogeneous distribution near the shearing zone and ARB is heavily affected by the chilling effect of the rolls on the sample surface. Warm torsion testing can in order to gain more control and reproducibility of the testing parameters. Despite the high strength and toughness of the UFG steels they tend to show reduced ductility due to their low work hardening rate. ${ }^{9-11)}$ On the other hand, it seems there is a consensus on the practical ways one can increase ductility of UFG metals. This could be doing by obtaining a final microstructure containing either a dispersion of fine second phase particles or

* Corresponding author: E-mail: welbert.ribeiro@nuclep.gov.br DOI: http://dx.doi.org/10.2355/isijinternational.53.909 by including a novel mechanism such as TRIP effect in the matrix. In this way, the initial work hardening rate of the alloy could be increased. ${ }^{12-15)}$ Song et al. ${ }^{16-18)}$ have demonstrated, furthermore, that it is possible to obtain a reasonable ductility in plain carbon steels processed to UFG microstructure if the microstructure consisted of a ferrite matrix and a dispersion of fine carbide particles. From the above, it seems that steel microstructure containing a ferrite matrix and a dispersion of fine particles is beneficial for a better ductility. Severe plastic deformation of a higher carbon steel content may then give the source of carbides promoting the formation of the desired microstructure. Nonetheless, few works have been dedicated to this subject since most studies on UFG refers to either Al alloys or IF steels. This may be due to the intrinsic experimental difficulties in applying the high total equivalent strains required to obtain UFG via ARB or ECAP in metals with higher yield stresses such as higher $\mathrm{C}$ steels. Irrespective of type of alloy, it seems most works deal either with the microstructure evolution during severe deformation or with mechanisms causing the formation of UFG. It seems, however, that few works has directly dealt with the effect of accumulated strain of the grain size itself and with effect of deformation temperature on the final grain size. The aims of this work are: a) to apply severe plastic deformation in medium carbon steels, and the method chosen here was torsion testing applying an ARB process schedule; ${ }^{19)}$ b) to compare microstructures, grain sizes and hardness values for low and medium carbon steels and c) study the effect of deformation temperature on final grain size. 


\section{Experimental Procedure}

Two plain C steels were used in this research: SAE-1010 carbon steel named from now on simply as "Low C" and a higher carbon steel, SAE-1045, designated herein as "Medium C". Their typical chemical compositions are shown in Table 1. Torsion experiments were used to apply severe plastic deformation to the samples. Cylindrical test specimens were machined from the as-received commercial bar to a gauge of $17.0 \mathrm{~mm}$ length and $6.4 \mathrm{~mm}$ diameter with the longitudinal axis parallel to the rolling direction. Several straining events or deformation passes were given to the specimens at temperatures of $500,550,600,650$ and $700^{\circ} \mathrm{C}$. At each straining event an equivalent strain equals to 0.8 was applied. The total accumulated strain per sample could be of up to 5.6 after testing. The aim here was to follow a deformation schedule close to that usually employed during ARB process experiments. A typical torsion experiment would have the following steps: a) heating up to test temperature at a rate of $3^{\circ} \mathrm{Cs}^{-1}$, b) keeping the sample soaking at this temperature for 5 minutes, c) deforming in torsion to an equivalent strain equals to 0.8 at strain rate of $10^{-1} \mathrm{~s}^{-1}$ and then d) cooling to room temperature. This process was repeated several times depend on the equivalent accumulated strain. However, as it will be seen, the Medium C steel fractured at a total deformation just higher than 2.0. For the Low $\mathrm{C}$ steel, two pass of 0.8 was purposely given in addition to the five originally intended, as explained in the next section. All tests were carried out using a MTS servohydraulic computer controlled machine with $250 \mathrm{Nm}$ load cell capacity.

Optical (OM) and scanning electron metalography (SEM) were carried out on a polished area near the gauge length surface along the specimen axis, since the shear strain is maximum at the surface. Average grain sizes were obtained by counting at least 200 grains giving an average error equal to $10 \%$, by the linear average intercept method. Vickers microhardness measurements were performed under $0.5 \mathrm{kgf}$ load penetration.

\section{Results}

Figure 1 shows the equivalent stress-strain curves obtained from torsion tests conducted at temperatures from 500 to $700^{\circ} \mathrm{C}$ and a total equivalent strain of 4.0. The shapes of the curves are quite different. The flow stress decreased with elevation in deformation temperature, a behavior expected. For the Medium C steel, stresses are higher than that for the Low $\mathrm{C}$ steel. However, softening during straining for the Medium C steel is more pronounced in low temperatures. This is deduced from the sharp drop in the stress level already during the first straining event in the temperature range from 500 to $550^{\circ} \mathrm{C}$. This effect is further enhanced in the course of the second event. With respect to

Table 1. Chemical compositions of steels (mass \%).

\begin{tabular}{lcccc}
\hline & $\mathrm{C}$ & $\mathrm{Mn}$ & $\mathrm{P}_{\max }$ & $\mathrm{S}_{\max }$ \\
\hline Low C & $0.10_{\max }$ & $0.30-0.50$ & 0.030 & 0.050 \\
Medium C & $0.43-0.50$ & $0.60-0.90$ & 0.030 & 0.050 \\
\hline
\end{tabular}

the temperatures higher than $600^{\circ} \mathrm{C}$, the stress-strain curves have a typical shape of metals undergoing dynamic recovery, that is, the stress reaches a plateau staying at this level irrespective of the total deformation, reaching a steady-state region. The differences between the yield stress at reloading and the flow stresses immediately before unloading become quite small in temperature higher than $600^{\circ} \mathrm{C}$. This suggests that any softening process take place during the interpass time, the structural change taking place in the samples after deformation should be affected in major part by strain accumulation and dynamic softening.

Figure 2 shows $\mathrm{OM}$ images for samples annealed at $900^{\circ} \mathrm{C}$ for microstructure homogenization. The pictures are typical of low plain carbon steel, largely ferritic fraction, and of medium plain carbon steel, a mixture of ferrite and pearlite.

Figure 3 shows SEM images for the Low C carbon steel after severe plastic deformation. In this figure the ferrite grains are fine and elongated; however, with the temperature increasing the grains take an equiaxial form. Arrows 1 and 2 indicate cementite lamellae fragmented and aligned in the deformation direction along grain boundaries. In the highest
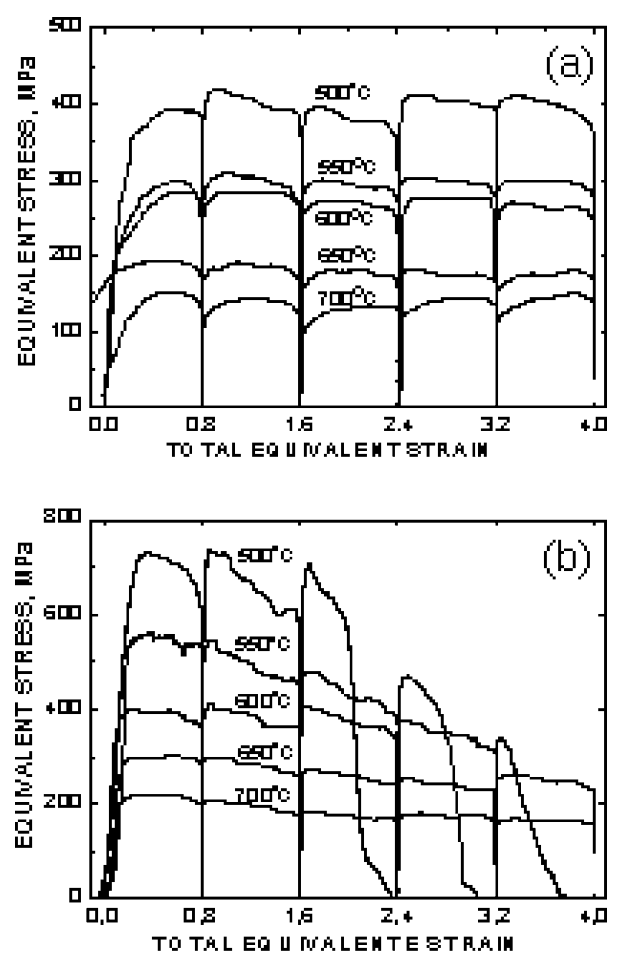

Fig. 1. Stress-strain curves of samples tested in torsion from temperatures of 500 to $700^{\circ} \mathrm{C}$. (a) Low C steel and (b) Medium C steel.

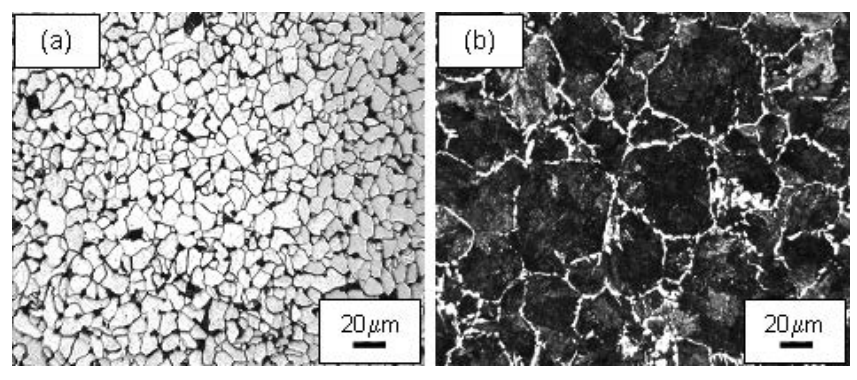

Fig. 2. OM images for Low C (a) and Medium C (b) steels in the as annealed condition. 


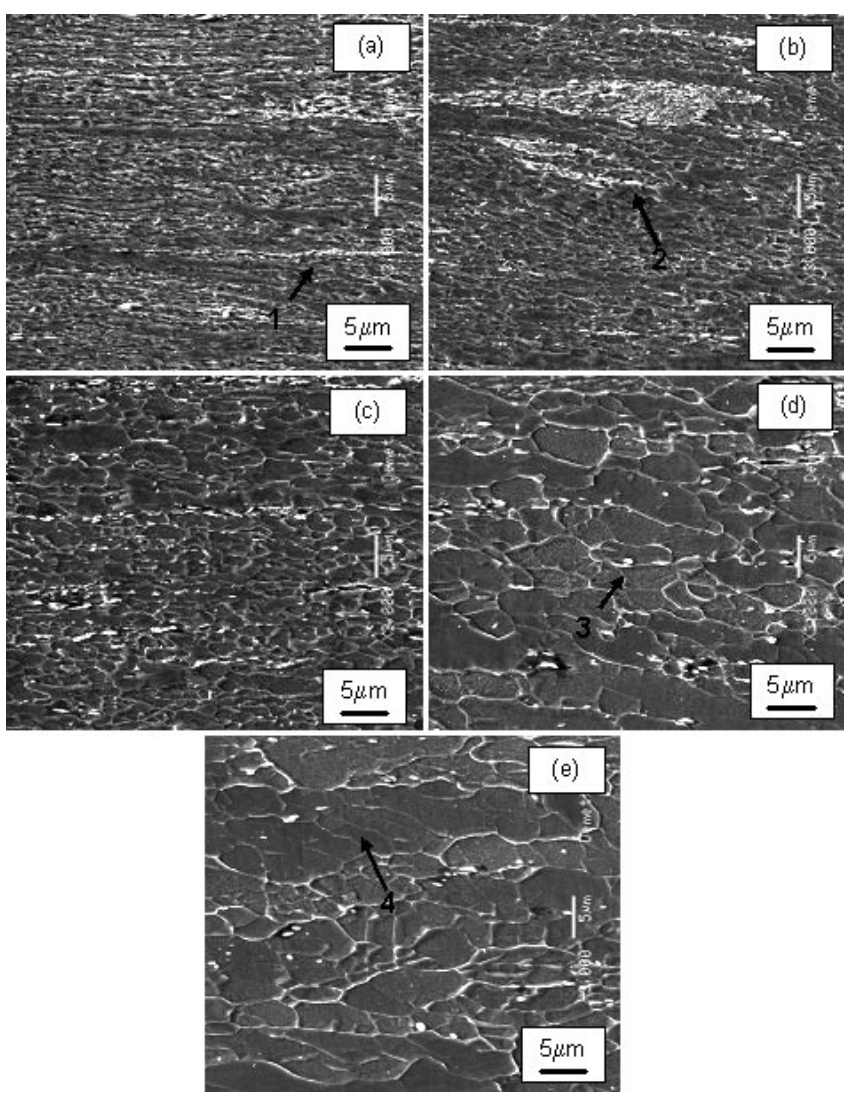

Fig. 3. SEM images for the Low $\mathrm{C}$ steel after grain refinement at $500^{\circ} \mathrm{C}(\mathrm{a}), 550^{\circ} \mathrm{C}(\mathrm{b}), 600^{\circ} \mathrm{C}(\mathrm{c}), 650^{\circ} \mathrm{C}(\mathrm{d})$ and $700^{\circ} \mathrm{C}(\mathrm{e})$.

deformation temperature the cementite are completely spheroidized and allocated in most part at the grain boundary, arrow 3. In some temperatures, Fig. 3(e), it's possible see some boundaries coalesced, arrow 4 . The SEM images for the Medium C can be seen in Fig. 4. The Medium C steel shows a mixture of fine ferrite grains and a dispersion of fine particles of fragmented and partially spheroidized cementite, some allocated at grain boundaries, arrows 1 and 2 ; with the increasing in deformation temperature the cementite particles became more coalesced and better dispersed. In the figures can be see that when the temperature increasing there are a greater spheiroidization of the cementite particles and these particles are preferentially located at ferrite grain boundaries.

Ferrite in Low C steels is almost $99 \%$ in weight and therefore dynamic recovery may be the dominant softening mechanism in the low deformation temperature, Fig. 2(a). As for the Medium C steel, the amount of pearlite in the steel is about $57 \%$ of its weight, Fig. 2(b). The remainder $43 \%$ is proeutectoid ferrite. Hence, at the testing temperature there will be $94 \%$ of ferrite; $34 \%$ proeuctetoid and $60 \%$ from the pearlite lamellae and $6 \%$ of $\mathrm{Fe}_{3} \mathrm{C}$ carbides. The pronounced decreasing stress seen in each deformation for the Medium C steel from 500 to $600^{\circ} \mathrm{C}$, Fig. 1, is due too to the cementite fragmentation in the course of deformation. Figs. 4(a) and 4(b) shows that cementite lamellaes are fragmented and in initial process of spheroidization. The remainder $94 \%$ of ferrite would behave in a similar manner shown for the Low $\mathrm{C}$ steel, that is, would softening by dynamic recovery. The cementite lamellae would spheroidise like seen before. The overall trend may be that the

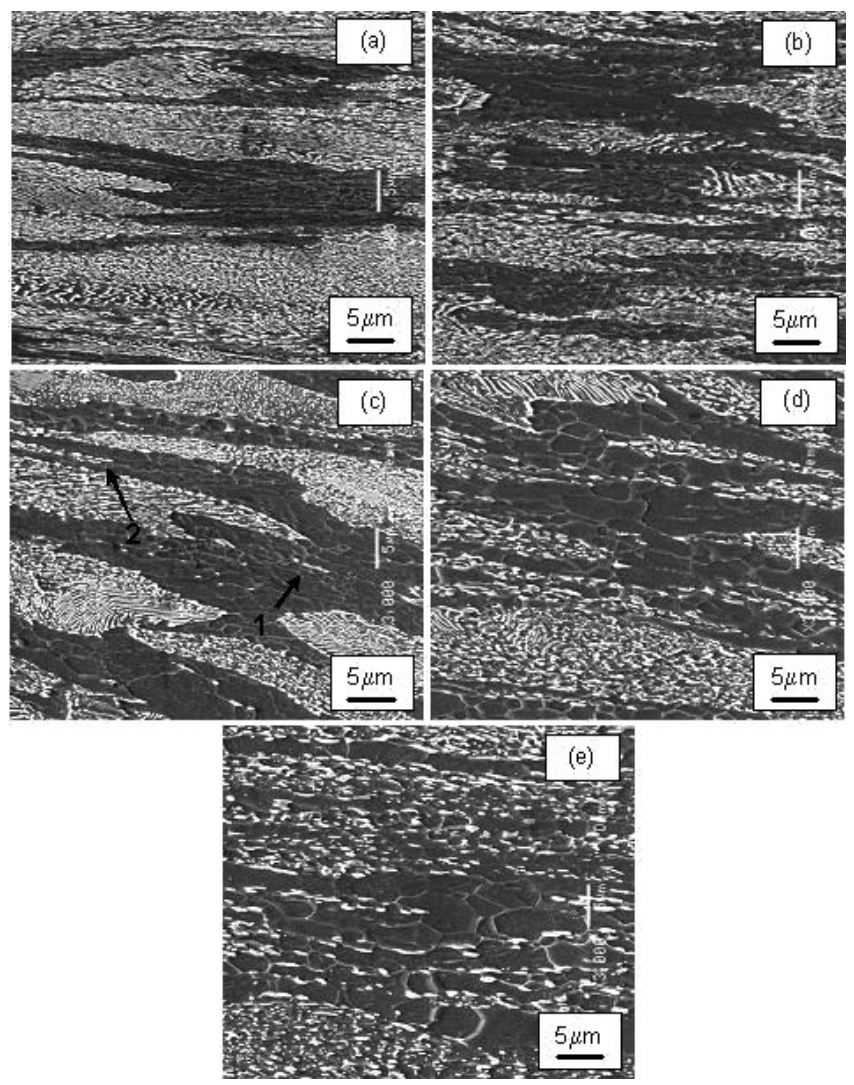

Fig. 4. SEM images for the Medium $\mathrm{C}$ steel after grain refinement at $500^{\circ} \mathrm{C}(\mathrm{a}), 550^{\circ} \mathrm{C}(\mathrm{b}), 600^{\circ} \mathrm{C}(\mathrm{c}), 650^{\circ} \mathrm{C}(\mathrm{d})$ and $700^{\circ} \mathrm{C}(\mathrm{e})$.

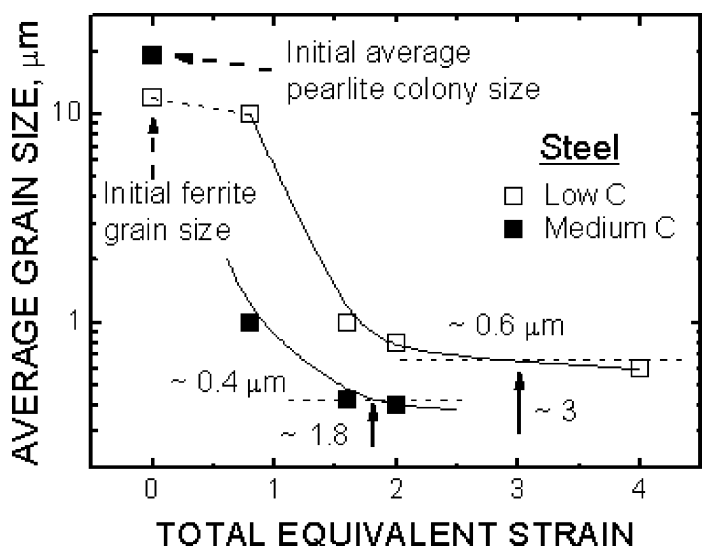

Fig. 5. Dependence of the average ferrite grain size on the total strain. Full arrows indicate total strains above which ultragrain refinement practically reached a constant value.

stress level would decrease continuously as a result of this fragmentation process and dynamic recovery till a steady state stress would be achieved. This level steady state stress would correspond to a microstructure made of dynamic recovered ferrite and fragmented and partially spheroidized $\mathrm{Fe}_{3} \mathrm{C}$ particles, this situation can be see in the highest deformation temperature for the Low C steel, Fig. 3(e). This point, however, could not be attained in the experiments for the Medium $\mathrm{C}$ steel because the samples consistently fractured at accumulated strains just over 2, as see in Fig. 1(b).

Figure 5 shows how the average ferrite grain size varies with the total equivalent strain applied to the samples. Ferrite grain size in the as annealed Low C steel was $12 \mu \mathrm{m}$. Deformation of 0.8 produced a ferrite grain of about $9 \mu \mathrm{m}$, 

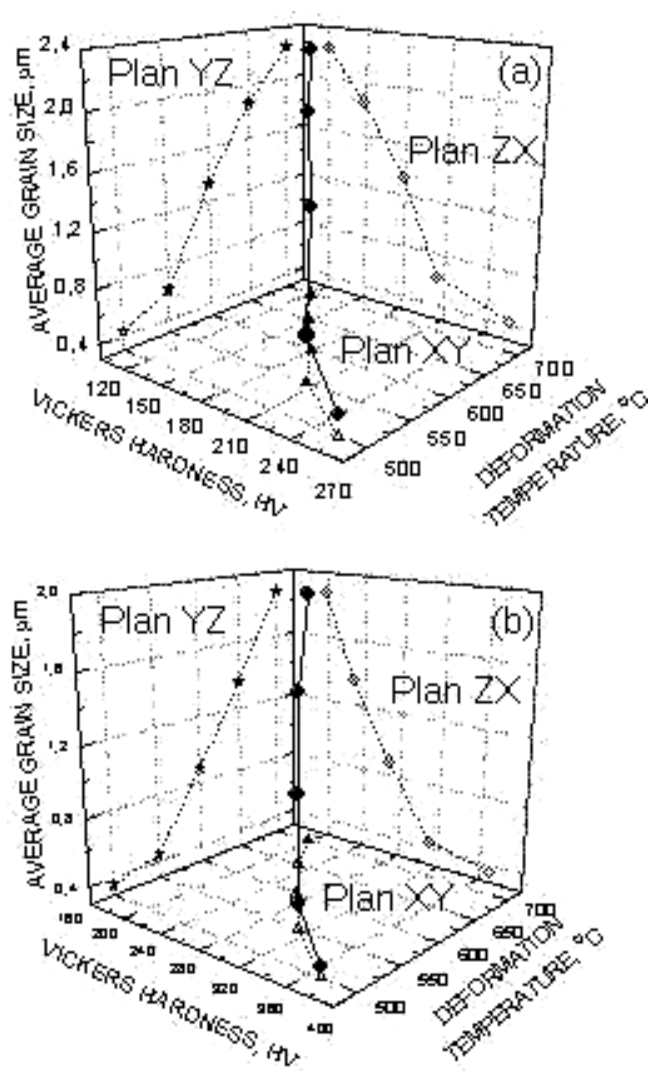

Fig. 6. Dependence of the average ferrite grain size and Vickers hardness on the deformation temperature for (a) the Low C steel e (b) the Medium C steel.

just about the same size as the annealed grains. Deformation up to a total of 1.6 led, however, to a significant reduction to sizes of the order of $0.8 \mu \mathrm{m}$. Further deformation to a total between 2 and 3 produced ferrite grain sizes of the order of $0.6 \mu \mathrm{m}$. A sample was then deformed to a total strain of 5.6 to verify whether deformation in excess of 4 would promote even more ferrite refinement. This was, however, not the case and the grain obtained after an accumulated strain of 5.6 was still $0.6 \mu \mathrm{m}$.

Hence, within the experimental the scatter, $\pm 10 \%$, not represented in the Fig. 5, may be possible to conclude that; a) there seems to be a critical deformation for the ultra-grain refinement, in the case of Low $\mathrm{C}$ steel studied here this deformation is around 1.6 ; b) a size around $0.6 \mu \mathrm{m}$ looks like a limiting size for the testing conditions for Low $\mathrm{C}$ steel and b) there seems to be a minimum strain above which fairly limited if any further grain refinement is achieved. The minimum strain at which this apparent limiting value would be reached equals to approximately 3 , taken here, as the average total strain for the last two passes. The Medium $\mathrm{C}$ steel followed a similar trend than the Low $\mathrm{C}$ steel, however the grain size reached the ultra-fine grained field after already the first deformation event, 0.8 equivalent strain. The final ferrite grain size was however smaller than that for the Low $\mathrm{C}$ steel in all accumulated deformation, that is a minimum grain size of about $0.4 \mu \mathrm{m}$, reached around a total strain of approximately 1.8 . Hence the conclusion that the higher the $\mathrm{C}$ content in the steels studied, the smaller critical deformation for grain refinement, the steady state grains size and the minimum strain for reached the steady state.

Figure 6 shows the dependence of the Vickers microhard-

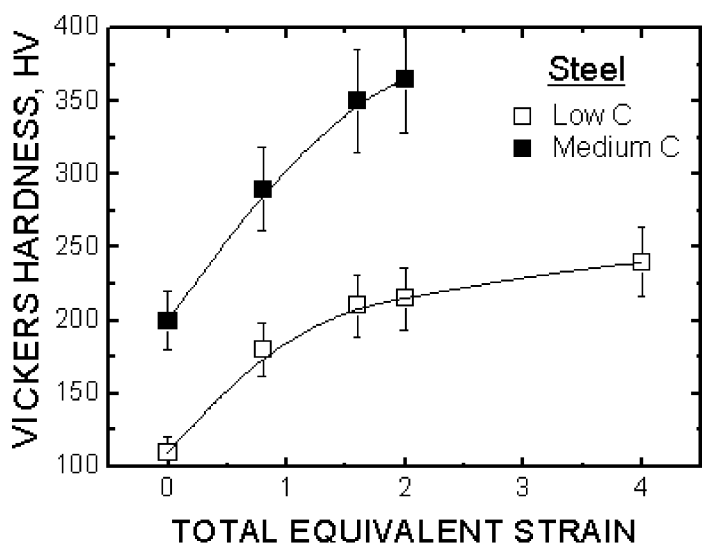

Fig. 7. Dependence of the hardness on the accumulated strain during torsion testing for Low $\mathrm{C}$ and Medium $\mathrm{C}$ steels.

ness and the ferrite grain size with deformation temperature. In the plan XY are represented the effect of deformation temperature on Vickers microhardness, in the plan ZX are represented the effect of the ferritic average grain size on microhardness and in the plan YZ the effect of deformation temperature on ferritic grain size. The general aspect in this representation is than when there is a increasing in deformation temperature there are a correspondent increasing on ferritic grain size and a decreasing on Vickers microhardness. The Medium $\mathrm{C}$ steel showed lower ferritic grain size in all deformation temperatures. At $700^{\circ} \mathrm{C}$ the average ferritic grain size in the Low $\mathrm{C}$ steel was near $2.2 \mu \mathrm{m}$, unlike in the Medium $\mathrm{C}$ steel this value was near $1.8 \mu \mathrm{m}$. The comparison on dependence of hardness with total equivalent strain for the two investigated steel can be seen on Fig. 7. The Mediun $\mathrm{C}$ steel showed higher hardness in all accumulated strain, as expected. Ferrite hardness increases with strain in all cases. However, in the Low $\mathrm{C}$ steel as for the grains size dependence, a saturation value for hardness seems to be achieved at strains between 2 and 3. Further deformation to strains of 5.6 gave a value of around $200 \mathrm{HV}$, indicating saturation.

\section{Discussion}

In the Fig. 6 can be seen that there are two different behaviors for the Lower $\mathrm{C}$ and Medium $\mathrm{C}$ steels with respect the grain refinement mechanism, curves in the plans (YZ) and (ZX). The UFG ferrite grains in the lower temperatures $\left(500\right.$ to $\left.550^{\circ} \mathrm{C}\right)$ are most likely produced by continuous dynamic recrystallization assisted by dynamic recovery, as pointed out earlier in the literature. ${ }^{20,21)}$ The continuous recrystallization implies the formation of low angle boundaries through the rearrangement of dislocations and the formation of high angle grain boundaries due to dislocation accumulation on the low angle boundaries increasing the misalignment between grains until a critical angle. However, in higher temperatures $\left(600\right.$ to $\left.700^{\circ} \mathrm{C}\right)$ the ferrite grain has a different morphology, Figs. 3 and 4, suggesting than the grain refinement process can be wispy different. The flow curves, Fig. 1, show than there isn't static recrystallization during the interpass time and it's well know that discontinuous dynamic recrystallization do not take place in carbon steels during a deformation event due its high stacking fault energy. If static and discontinuous recrystallization 
did not occur the continuous dynamic recrystallization can take place. In deformation at 600,650 and $700^{\circ} \mathrm{C}$ the diffusion is fast enough to enable significant high angle boundaries migration, and the ferrite grains were coarser compared to those at 500 and $550^{\circ} \mathrm{C}$. However, in the higher temperatures the spheroidization of the fragmented cementites lamelaes are in advanced state, an take an additional contribution for the grain refinement by means of Zener pinning mechanism, reducing the grain migration in the higher carbon steel when compared to the lower carbon steel.

The values for ferrite microhardness can be correlated to strengthening from increases in dislocation density and decreases in ferrite grain size. It seems that early increase in hardness has to do with the increase the density of geometrically necessary dislocation required to generate low angle grain boundaries. The increasing in the deformation strain promote the formation of high angle grain boundaries, the grain size remains approximately constant and hardness does not change much even at strains as high as 5.6 indicating occurrence of dynamic recovery. As for the Medium $\mathrm{C}$ steel, the same mechanism of ferrite grain refinement seems to be applicable. The higher starting hardness as compared to the Low $\mathrm{C}$ values may be due to the higher $\mathrm{C}$ content at the initial ferrite grains, since at least $34 \%$ in weight of this steel is proeuctetoid ferrite. As deformation proceeds, work hardening and refinement of ferrite grains and hence the presence of more ferrite grain boundaries per unit volume may account for the increase in hardness. At the same time, cementite lamellaes becomes fragmented producing small particles. This softens the matrix. However, as the results show an increase in hardness at least in the early stages of deformation, the net result must be influenced more by the increase in average dislocation density than in softening via cementite fragmentation.

In summary, ferrite grains are reduced by severe plastic deformation. First, work hardening promotes this decrease in grain size by generating the geometric necessary dislocation to create new ferrite grain boundaries. In the presence of fine carbide particles as in the case of the Medium C steel, this dislocation density seems to be higher partially maybe by the restricted shorter length a dislocation may travel, inhibiting some dynamic recovery. The interspace particle length seems to affect grain size by limiting somehow its growth. The two effects together; work hardening and grain boundary formation plus impingement at partially spheroidized particles of $\mathrm{Fe}_{3} \mathrm{C}$, seem to determine a minimum ferrite grain size and a critical accumulated strain above which very little if any significant grain refinement is obtained.

Experimental evidence has suggested thus far that a) average ferrite grain size decreases with increases in accumulated strain; b) a minimum value for grain size is achieved at a critical strain above which no significant further grain refinement is obtained; c) as $\mathrm{C}$ content increases, this minimum grain size and critical strain decrease; d) the average grain size increase with deformation temperature increment and e) the higher carbon content stabilize the grain size with increasing temperature.

The two steels tested here represent, essentially, two different microstructures: a nearly $100 \%$ ferritic steel and another with ferrite + pearlite structure. In the Low C steel, dynamic recovery is the relevant softening mechanism whereas in the Medium C steel, softening occurs by dynamic recovery and cementite fragmentation. Therefore, it is expected that final grain sizes in the Low $\mathrm{C}$ steel would be solely determined by the interactions between dislocations whereas in the case of the Medium $\mathrm{C}$ steel, the final sizes would be determined by the same interactions added however by the effects of the interactions between dislocations and carbide particles. In the case o the Low $\mathrm{C}$ steel, the average dislocation density can be described by the KocksMecking model, ${ }^{22)}$ that is,

$$
\frac{d \rho}{d \varepsilon}=C_{1}-C_{2} \rho
$$

The work hardening term is $C_{1}=1 /(b \Lambda)$, b being the Burgers vector, $\sim 2.5 \times 10^{-10} \mathrm{~m}$, and $\Lambda$ is the mean free path a dislocation can glide. The recovery rate, $C_{2}$, is a function of the strain rate and test temperature. Integration of Eq. (1) gives

$$
\rho=\frac{C_{1}}{C_{2}}\left[1-\exp \left(-C_{1} \varepsilon\right)\right] .
$$

Allowing for $H_{\nu} \equiv \rho$ and for the average ferrite grain size to be related to the mean dislocation density by $l \propto 1 / \sqrt{\rho}$, the analysis of the expressions above indicate that as the strain increases, $\rho$ tends to a limiting value $\rho=C_{1} / C_{2}$. Also, in this case, the mean ferrite grain size would tend to a lower limiting value of $l=1 / \sqrt{C_{1} / C_{2}}$. This is in agreement with observations from Fig. 5 .

Figure 8 shows than the experimental data for the Low C steel can be fitted to expressions of the types

$$
H_{v}=100+125 \sqrt{1-\exp (1.8 \varepsilon)}
$$
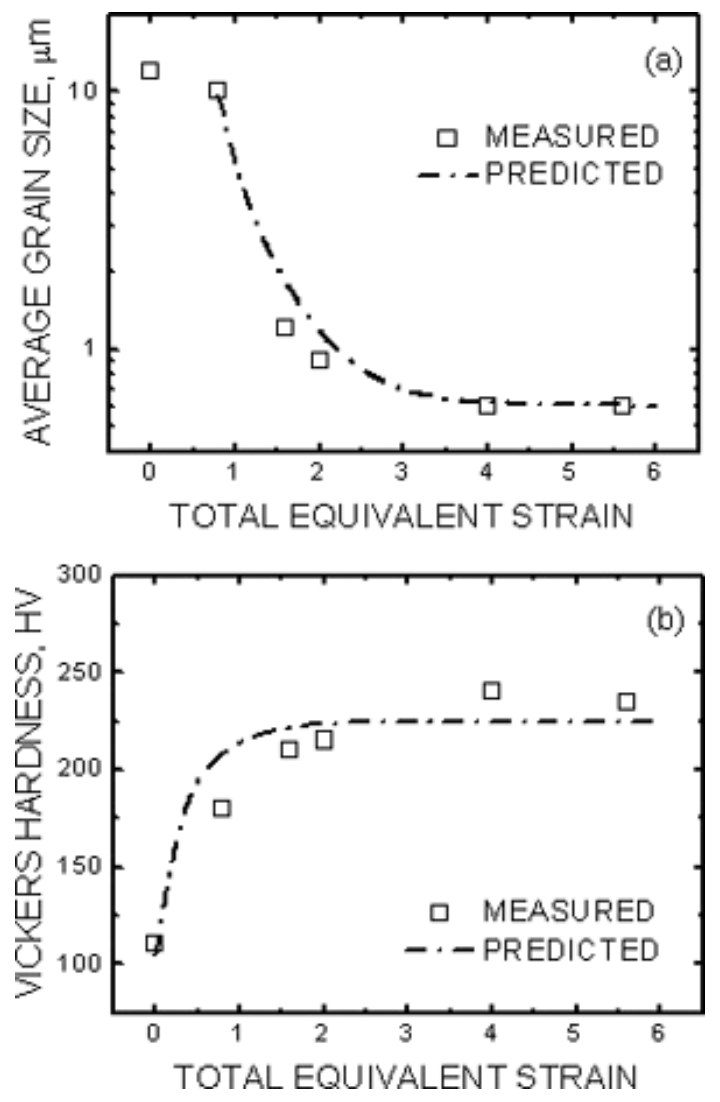

Fig. 8. Fitting of experimental data by means of Kocks-Mecking model for the dependence of $\rho$ on $\varepsilon$ for the Low C steel. 
and

$$
d_{\alpha}=10 \mu m-9.6 \mu m \sqrt{1-\exp (1.8 \varepsilon)}
$$

The semi-empirical expressions above incorporate an exponential decay term and a square root function, as provided in Eq. (2).

As the average dislocation density increases, the average grain size decreases. Figure 8(a) shows the experimental data for grain sizes. The dotted line is the predicted values for the variation in grain sizes from approximately 10 to 0.6 $\mu \mathrm{m}$. The agreement between experimental and predicted values is quite reasonable. It seems then from the experimental as well from the model view point that there is a limiting grain size for a given test condition. This limiting value should, however, change with test strain rate and temperature since the value of the recovery term in Eq. (1) should vary with these changes.

It should also be expected that, as the recovery rate becomes more effective, that is, as temperature increases or strain rate decreases, the value of a steady state $\rho$ would decrease, leading to larger limiting grain size values. Conversely, this limiting grain size would decrease if either temperature decreased or strain rate increased.

In the case of the Medium $C$ steel, the value of $C_{1}$ must be further considered. The mean free dislocation path can be described as ${ }^{22}$ )

$$
\frac{1}{\Lambda}=\frac{1}{l}+\frac{1}{t}+C_{3} \sqrt{\rho}
$$

where $t$ is the average $\mathrm{Fe}_{3} \mathrm{C}$ particle distance. Consequently,

$$
C_{1}=\frac{1}{b}\left(\frac{1}{l}+\frac{1}{t}+C_{3} \sqrt{\rho}\right) .
$$

It is then seen that at the onset of deformation $C_{1}$ is mostly determined by the grain size component. However, as soon as fragmentation starts, the mean interparticle distance term will give an extra contribution increasing the value of $C_{1}$. Therefore, $C_{1}$ increases with strain or, equivalently, with mean dislocation density. This leads to $C_{1}$ values for the medium $\mathrm{C}$ steel which are in fact numerically higher than that for the low $\mathrm{C}$ steel. As the accumulated deformation becomes larger, $\rho$ will tend to the value of the ratio $C_{1} / C_{2}$, as just mentioned. However, this ratio will be larger than that for the low $\mathrm{C}$ steel and it will be also largely influenced by the mean interspace distance between $\mathrm{Fe}_{3} \mathrm{C}$ particles. Therefore, $\rho_{1045}>\rho_{1010}$, as suggested at Figs. 5 and 7 and the average ferrite grain size should also be smaller.

In summary, analysis of Eq. (1) gives support for the experimental findings reported so far regarding ferrite grain sizes and for the existence of a "critical strain" as already described. However, as observed, the value of the critical strain decreases as the $\mathrm{C}$ content increases. This effect may be explained by analyzing the recovery term of Eq. (1). In fact, $C_{2}$ depends on test strain rate and temperature therefore it can be considered as a direct function of $Z=\dot{\varepsilon}[Q /(R T)]{ }^{23)} C_{2}$ becomes larger as $Z$ increases. The activation energy $Q$ here should be largely related to that required to move dislocations in the absence of particles. However, as $\mathrm{Fe}_{3} \mathrm{C}$ partially spherodizes, these particles become barriers to free glide in effect raising the value of $\mathrm{Q}$. If that is the case, the value of $C_{2}$ would increase and the value of $\rho$, for this reason, would achieve a virtual steady state value at strains lower than the required for the Low $\mathrm{C}$ steel, in agreement with observations just reported.

\section{Conclusions}

A SAE 1010 low plain carbon steel and a SAE 1045 medium plain carbon steel were severe plastic deformed by means of warm torsion testing. The main conclusions to this work can be listed as follows:

a) Severe deformation via torsion tests can produce ultrafine ferrite grains;

b) The size of theses grains varies with $\mathrm{C}$ content. Minimum grain size of the order of $0.6 \mu \mathrm{m}$ was obtained for the low $\mathrm{C}$ steel. As the $\mathrm{C}$ content increased, the minimum grain size decreased. Average ferrite grain size of the order of $0.4 \mu \mathrm{m}$ was obtained for the medium $\mathrm{C}$ steel;

c) There is a minimum "critical strain" above which no significant grain refinement is further achieved. This critical strain is of the order of 3 for the low $\mathrm{C}$ steel and of 1.8 for the medium $\mathrm{C}$ steel;

d) There is a minimum critical strain for grain refinement. This strain decrease with the increasing in carbon content;

e) The experimental findings can be qualitatively analyzed and explained in terms of the Kocks-Mecking model for the dependence of $\rho$ on $\varepsilon$.

\section{Acknowledgements}

The authors acknowledge the funding agencies CAPES, CNPq and FAPEMIG for providing financial support throughout the research.

\section{REFERENCES}

1) Y. Saito, H. Utsunomiya, N. Tsuji and T. Sakai: Acta Mater., 47 (1999), 579.

2) N. Tsuji, Y. Saito, H. Utsunomiya and S. Tanigawa: Scr. Mater., 40 (1999), 795.

3) V. Segal: Mater. Sci. Eng. A, 271 (1999), 322.

4) B. Q. Han and S. Yue: J. Mater. Process. Technol., 136 (2003), 100.

5) Y. Ivanisenko, W. Lojkowski, R. Z. Valiev and H. J. Fecht: Acta Mater., 51 (2003), 555.

6) R. Song, D. Ponge, D. Raabe, J. G. Speer and D. K. Matlock: Mater. Sci. Eng. A, 441 (2006), 1.

7) W. R. Calado and R. A. N. M. Barbosa: ISIJ Int., 50 (2010), 1471.

8) M. C. Zhao, F. Yin, T. Hanamura, K. Nagai and A. Atrens: Scr. Mater., 57 (2007), 860.

9) N. Tsuji, Y. Ito, Y. Saito and Y. Minamino: Scr. Mater., 47 (2002), 893.

10) N. Tsuji, N. Kamikawa, R. Ueji, N. Takata, H. Koyama and D. Terada: ISIJ Int., 48 (2008), 1114.

11) R. Song, D. Ponge and D. Raabe: ISIJ Int., 45 (2005), 1721.

12) Y. Tomota, N. Akinori and N. Tsuchida: ISIJ Int., 48 (2008), 1107

13) J. William: ISIJ Int., 48 (2008), 1063.

14) S. V. S. Narayana Murty and S. Torizuka: ISIJ Int., 48 (2008), 1088.

15) N. Tanaka, Y. Ohtake, K. Kita, K. Kitagawa and N. Tsuji: Scr. Mater., 60 (2009), 590.

16) R. Song, D. Ponge, D. Raabe and R. Kaspar: Acta Mater., 53 (2005), 845.

17) R. Song, D. Ponge and D. Raabe: Acta Mater., 53 (2005), 4881.

18) R. Song, D. Ponge and D. Raabe: Scr. Mater., 52 (2005), 1075.

19) A. L. M. Costa, A. C. C. Reis, L. Kestens and M. S. Andrade: Mater. Sci. Eng. A, 405 (2005), 279.

20) B. Eghbali: Mater. Lett., 61 (2007), 4006.

21) B. Eghbali, A. Z. Abdollah and P. D. Hodgson: Mater. Sci. Eng. A, 462 (2007), 259.

22) U. F. Kocks and H. Mecking: Prog. Mater. Sci., 48 (2003), 171.

23) N. Yazdipour, C. H. J. Davies and P. D. Hodgson: Comp. Mater. Sci., 44 (2008), 566. 